\title{
Beliefs about Medicines among a Sample of Iraqi patients with Psoriasis
}

\author{
Sarah H. Abdulridha, MSc ${ }^{1}$; Dheyaa J. Kadhim, PhD'; Sarmad A. Abdul Razzak, M.B.Ch.B, D.V.D, F.I.B.M.S. ${ }^{3}$ \\ ${ }^{1}$ Ministry of Health and Environment, Baghdad, Iraq; \\ ${ }^{2}$ Department of Clinical Pharmacy, College of Pharmacy, University of Baghdad, Baghdad, Iraq \\ ${ }^{3}$ Center of Dermatology and Venereology, Medical City, Baghdad, Iraq
}

\begin{abstract}
Objectives: This study aimed to evaluate beliefs about use of medications for a sample of Iraqi psoriasis patients, and to examine the association between these beliefs and selected patient's related factors.

Methods: This cross-sectional study included 300 patients with diagnosed psoriasis. Participants were recruited at the center of Dermatology and Venereology, Medical City in Baghdad, the capital city of Iraq. Patients' mean age was 35.15years ( \pm 10.54$)$. Beliefs about medicines were measured by the Arabic version of Beliefs about Medicines Questionnaire.

Results: Most the patients (76.7\%) had strong beliefs in the need (acceptance beliefs) for their psoriasis medicines (specific-necessity score higher than specific-concern), whereas $15.0 \%$ of patients had specific-concern score higher than specific-necessity and $8.3 \%$ of patients had specific-necessity score equal to specific-concern. At the same time, $74.4 \%$ of the patients believed that the medicines disrupt their lives and (35.6\%) of them had concerns about the possibility of becoming addicted on these medicines. Many other patients were worried about the long-term consequences of the medicines (58.7\%). In addition, 31.0\% of the participants believe that all medicines are poisoning, and that they do more harm than good. Finally, many of the participants believed that physicians prescribe too many medicines (46.7\%), and they can minimize the number of prescribed medicines by spending more time with the ir patients (32.6\%).

Conclusions: Female gender and longer disease duration have direct association with specific necessity, while psoriasis severity has a direct association with specific concern. In conclusion, Beliefs about medications and habit strength are important modifiable drivers to enhance adherence and clinical outcomes in the control of psoriasis.
\end{abstract}

Keywords: Psoriasis, Specific concern, Beliefs about medicine, Specific necessity, Iraq

\section{Introduction}

Psoriasis is a chronic ${ }^{(1)}$, complex autoimmune inflammatory disease (2), characterized by remission and exacerbation (3). Prevalence of psoriasis is variable ${ }^{(4)}$, ranging approximately 1 to $3 \%$ across the world ${ }^{(5)}$. Common genetic and inflammatory pathways have been implicated in psoriasis ${ }^{(6)}$. Several chemical products and medicines are associated with the exacerbation and/or triggering of psoriasis which includes lithium (4), betablockers, antimalarial drugs, nonsteroidal anti-inflammatory agents, and tetracycline ${ }^{(7)}$. Psoriasis has a variety of different presentations ${ }^{(8)}$, characterized by red plaques with adherent silvery-white scales, and typically has symmetrical distribution across the body ${ }^{(9)}$. Topical treatments are generally used as first-line therapy for most types of psoriasis ${ }^{(10)}$, which generally provide a high efficacy-to-safety ratio ${ }^{(11)}$. Moderate-to-severe psoriasis is usually treated with systemic therapies, such as methotrexate (MTX) or biologics ${ }^{(12)}$.

Medicines have a fundamental role in the control of chronic diseases. However, it is recognized that only half of the patients with chronic diseases take their medicines as prescribed ${ }^{(13)}$. In dermatological diseases, the negative therapeutic outcomes is related to non-adherence to treatment that is the main factor

Corresponding author: Sarah H. Abdulridha, MSc Ministry of Health and Environment, Baghdad, Iraq E-mail: sarahaider801@gmail.com of the treatment success ${ }^{(14)}$. Medication adherence is affected not just by patient-related factors (like disease characteristics and demographics), but also additionally by patients' beliefs about the medications and the use of mass media ${ }^{(15)}$. The key factor that has effects on patients' adherence is their common views related to medicines due to the fact it can overtake many other factors (16). Consequently, taking patient's beliefs regarding their medication into consideration is a significant factor impacting adherence of patients to their medications ${ }^{(16)}$. Complex diseases, like psoriasis, are associated with significant medication issues. In contrast to various other long-term conditions, there is evidence to claim that a huge proportion of people having psoriasis think that their condition is not really treated completely aggressively. Typically, peoples with psoriasis might switch from one therapeutic approach to another. Accordingly, they could also have concerns regarding undesirable medication adverse effects, in addition to uncertainty concerning the level of disease control obtained by their medication ${ }^{(17)}$.

The main innovation of the Beliefs about Medicines Questionnaire (BMQ) is the direct quantification of patients' beliefs about drugs and their use, which is a significant factor that affects patients' adherence for their prescribed medication. The BMQ may recognize people at high risk of nonadherence and allow patients to discuss their beliefs, thus providing opportunities to improve medication adherence ${ }^{(18)}$. 
Accordingly, the aim of this study was to evaluate beliefs about medications in a sample of Iraqi psoriasis patients and to determine the possible relation between medications belief and some patient's-related factors.

\section{Methods}

Design and Settings: The current cross-sectional study was conducted over a period of fourth months from (October 2019 to January 2020). Eligible participants were recruited the Center of Dermatology and Venereology, Medical City in Baghdad, which represent the main center of dermatology in the region.

Participants: Patients that are already diagnosed with psoriasis and agreed to participate.

\section{Inclusion criteria:}

1-Patients age $\geq 18$ years who were willing to participate in the study.

2-The duration of the disease is $\geq 6$ months to give his/her opinion about medications that had been used for quite some time.

3-Prescribed pharmacological treatment for psoriasis.

\section{Exclusion criteria}

1-Patient with cognitive, speech, or hearing deficit that would affect questions' understanding.

2-Patient with other skin disorders.

3-Concomitant other significant diseases (such as diabetes mellitus, hypertension, chronic lung disease, chronic renal failure, heart disease and stroke).

4-Pregnant or lactating women.

5-Patients who provide incomplete information.

The data necessary for the current study were collected by using a data sheet for each patient involved in the study:

1-Demographic data: age, gender, level of education, marital status, residence place and monthly income.

2-Disease-charecteristics: type of psoriasis, duration of psoriasis, clinical severity of the psoriasis [measured using psoriasis area severity index (PASI); Mild if PASI < 3, Moderate if $3 \leq \mathrm{PASI}<10$, and severe if PASI $\geq 10]^{(19)}$ and current medications used for psoriasis.

Survey: Belief about medicines was estimated by using an Arabic version of the $\mathrm{BMQ}$, which was translated English. It is a novel method for estimating cognitive medical representations, and to get the best understanding of patients' perceptions about medicines ${ }^{(20)}$.

The BMQ is an 18-item questionnaire that consists of two domains: (1) Beliefs about Medicines Questionnaire in general (BMQ-General) and (2) Beliefs about Medicines Questionnaire for specific conditions (BMQ-Specific) ${ }^{(21)}$. The BMQ items were measured with a 5-point Likert scale (one is strongly disagree; five is strongly agree; multiplied by a factor of five for this study, which was used to evaluate standard (Harm and Overuse subscales) and certain (Necessity and Concerns subscales) beliefs about medicines ${ }^{(22)}$. Belief about Medicines Questionnaire -Specific is composed of two five-item aspects that assess beliefs on the necessity of prescribed medications (Specific-Necessity) and considerations about prescribed medications depending on beliefs about the side effects of medications, risk of dependence and long term toxicity (Specific-Concerns) ${ }^{(20)}$.

For individual items, the obtained scores were summed within each scale to give a total scale score. The score of both (specificnecessity and specific-concern) domains ranged from 5-25. The higher the score in specific-necessity domain, the higher the patients' belief in the importance of medications to them. On the other hand, a high score in the specific concern domain suggests that patients are worried and concerned about their current medications ${ }^{(23)}$.

The scores of general parts (overuse / harm) ranged from 4-20 where high score of the domain suggests an overall negative perception toward medications ${ }^{(23,24)}$.

\section{Ethical approval}

The research proposal which explains the objectives behind the current study and the intended methods for collecting data as administered to the College of Pharmacy, the University of Baghdad, were reviewed and approved from the scientific and ethical committee. Additionally, an approval was obtained from the Ministry of Health. Finally, consent approval from the patients to participate in the study was obtained verbally. No incentives were offered to the participants.

\section{Statistical analysis.}

The analyses were done by using the Statistical Package for the Social Science (SPSS, version 22, IBM, New York, USA). Descriptive statistics (means, standards deviations, frequencies and percentages) of the participants and disease were calculated. Multiple linear regression was used to measure the association between BMQ scores and multiple independent variables (socio-demographic and disease characteristics).

\section{Results}

A total of 300 patients (188 male and 112 female) where involved in this study. The mean age of patients was 35.16 years $( \pm 10.55)$. The sociodemographic characteristics of the participants are illustrated in (Table 1$)$. 
Table 1: The sociodemographic features of the patients

\begin{tabular}{|c|c|c|c|}
\hline Item & Subcategory & Frequency (N) & $\%$ \\
\hline \multirow[t]{2}{*}{ Gender } & Male & 188 & 62.7 \\
\hline & Female & 112 & 37.3 \\
\hline \multirow[t]{4}{*}{ Education level } & Illiterate & 20 & 6.7 \\
\hline & Primary school & 84 & 28.0 \\
\hline & Secondary school & 104 & 34.7 \\
\hline & College degree & 92 & 30.7 \\
\hline \multirow[t]{4}{*}{ Social status } & Single & 80 & 26.7 \\
\hline & Married & 207 & 69.0 \\
\hline & Divorced & 8 & 2.7 \\
\hline & Widow & 5 & 1.7 \\
\hline \multirow[t]{2}{*}{ Having children } & Yes & 106 & 35.3 \\
\hline & No & 194 & 64.7 \\
\hline \multirow[t]{2}{*}{ Living Place } & Rural & 46 & 15.3 \\
\hline & Urban & 254 & 84.7 \\
\hline \multirow[t]{5}{*}{ Work Status } & Employee & 92 & 30.7 \\
\hline & Student & 26 & 8.7 \\
\hline & Retired & 91 & 30.3 \\
\hline & Self-employed & 6 & 2.0 \\
\hline & Wife House & 85 & 28.3 \\
\hline \multirow{3}{*}{$\begin{array}{l}\text { Monthly income } \\
\text { (Iraqi million dinars) }\end{array}$} & $<0.5$ & 117 & 39.1 \\
\hline & $0.5-1.0$ & 84 & 28.1 \\
\hline & $>1.0$ & 98 & 32.8 \\
\hline \multirow[t]{2}{*}{ Smoker } & Yes & 84 & 28.0 \\
\hline & No & 216 & 72.0 \\
\hline \multirow[t]{2}{*}{ Alcohol drinker } & Yes & 17 & 5.7 \\
\hline & No & 283 & 94.3 \\
\hline
\end{tabular}

The most common type of psoriasis was Vulgaris (77.7\%), followed by erythrodermic and psoriatic arthritis types (6.3\% each) as shown in (Figure 1).

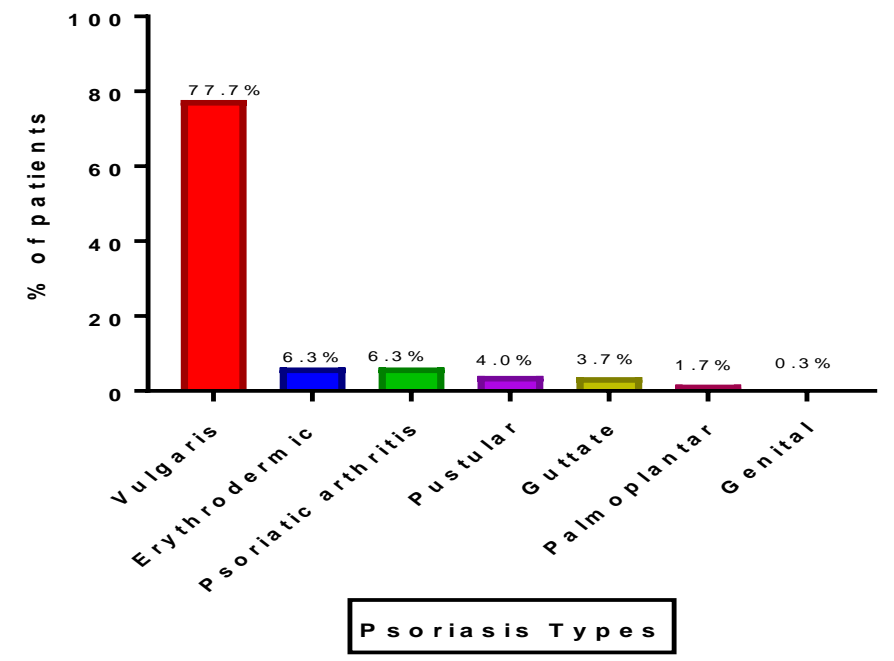

Figure 1: The types of psoriasis affected the participating patients 
The most commonly used medications to treat psoriasis were topical steroids, systemic etanercept (biological therapy) (Table 2)

Table 2: The prescribed medications for patients

\begin{tabular}{|l|l|l|}
\hline Medications & \multicolumn{2}{l|}{ Frequency (N) } \\
\hline Topical treatment and phototherapy & \multicolumn{2}{l|}{ Percent (\%) } \\
\hline Topical steroids & 189 & 63.0 \\
\hline Vaseline & 124 & 41.3 \\
\hline Phototherapy & 7 & 2.3 \\
\hline Cinnamon shampoo & 6 & 2.0 \\
\hline Zinc oxide ointment & 6 & 2.0 \\
\hline Topical calcineurin inhibitors & 3 & 1.0 \\
\hline Topical coal tar & 2 & 0.7 \\
\hline Systemic treatment & 185 & \\
\hline Etanercept & 68 & 61.7 \\
\hline Methotrexate & 68 & 22.7 \\
\hline Folic acid & 17 & 22.7 \\
\hline Cyclosporine & 5 & 5.7 \\
\hline Acitretin & 6 & 1.7 \\
\hline Antihistamines & 1 & 2 \\
\hline Isoniazid & 1 & 0.3 \\
\hline Aprelimast & 1 & 0.3 \\
\hline Adalimumab & 0.3 \\
\hline
\end{tabular}

The mean disease duration of the patients was 13.12 years ( \pm 8.60$)$. Severity of psoriasis disease (PASI) and affected BSA are shown in (Table 3).

Table 3: Descriptive characteristics of the disease and patients.

\begin{tabular}{|l|l|l|l|l|}
\hline Characteristic & Minimum & Maximum & Mean & Std. Deviation \\
\hline Duration of the Disease (years) & 0.5 & 43.0 & 13.12 & 8.60 \\
\hline Severity index (PASI) & 0.5 & 36.0 & 8.74 & 7.15 \\
\hline BSA $\left(\mathbf{m}^{2}\right)$ & 1.0 & 90.0 & 17.25 & 17.39 \\
\hline
\end{tabular}

Total $\mathrm{N}=300$. $\mathbf{P A S I}=$ Psoriasis area severity index. BSA=Body surface area

About half of the participants (47\%) had moderate PASI while one-third (34.3\%) had severe PASI as shown in (Figure 2 ).

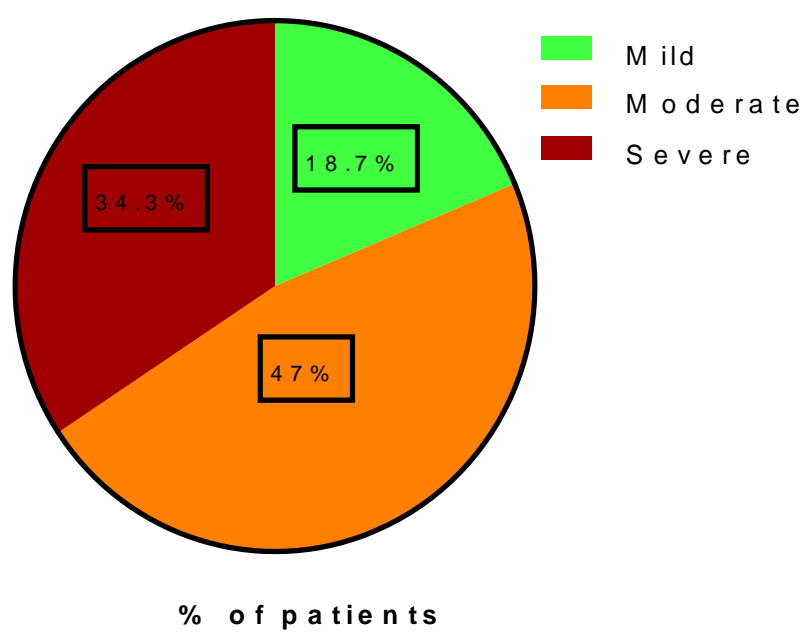

Figure 2: Distribution of patients according to the PASI (Psoriasis Area and Surface Index).

Disease severity: Mild: PASI < 3; Moderate: PASI 3 to $<10$; Severe=PASI $\geq 10$. 
The sub-scores of BMQ for psoriatic patients are shown in (Table 4). The majority of patients (76.7\%) had strong beliefs in the necessity (acceptance beliefs) about their psoriasis medicines (specific-necessity score greater than specific-concern), whereas $15.0 \%$ of patients had specific-concern score higher than specific-necessity while $8.3 \%$ of patients had specific-necessity score equal to specific-concern.as shown in (Table 5).

Table 4: The means of Beliefs about Medicine (BMQ)

\begin{tabular}{|r|r|r|}
\hline Item & Mean & Std. Deviation \\
\hline Specific necessity & 21.04 & 3.67 \\
\hline Specific concern & 16.65 & 4.22 \\
\hline General-Harm & 11.41 & 2.80 \\
\hline General-Overuse & 12.01 & 2.29 \\
\hline
\end{tabular}

Table 5: Patient Beliefs about Medicines: Necessity-concern differential

\begin{tabular}{|l|l|l|}
\hline Necessity - concern differential & Numbers & Percentage \\
\hline Necessity > concern & 230 & $76.7 \%$ \\
\hline Necessity < concern & 45 & $15.0 \%$ \\
\hline Necessity = concern & 25 & $8.3 \%$ \\
\hline
\end{tabular}

About $90 \%$ of the participants believed that their health relies on their medications and $89.7 \%$ perceived that their medications protect them from becoming worse. Thus, the majority believed that psoriasis medicines are necessary. At the same time, about three quarter believed that the medicines disrupt their lives (74.7\%) and (35.6\%) of them had concerns about becoming addicted to these medicines. Many others were worried about the long-term consequences of the medicines (58.7\%). The surprising findings were $(31 \%)$ of the participants believe that all medicines are poisoning, and they do harm more than good. Finally, many participants believed that physicians prescribe too many medicines $(46.7 \%)$ and that they can minimize the number of prescribed medicines by spending more time with their patients (32.6\%) (Table 6). 
Table 6: The participant Beliefs about Medicines (BMQ) status

\begin{tabular}{|c|c|c|c|c|c|c|}
\hline & BMQ item & $\begin{array}{l}\text { Strongly } \\
\text { disagree }\end{array}$ & Disagree & Uncertain & Agree & $\begin{array}{l}\text { Strongly } \\
\text { agree }\end{array}$ \\
\hline & Specific-Necessity (BMQ-SN) & $\mathrm{N}(\%)$ & $\mathrm{N}(\%)$ & $\mathrm{N}(\%)$ & $\mathrm{N}(\%)$ & $\mathrm{N}(\%)$ \\
\hline 1 & $\begin{array}{l}\text { My life would be impossible without my } \\
\text { medicines. }\end{array}$ & 0 & $30(10.0)$ & $23(7.7)$ & $91(30.3)$ & $156(52.0)$ \\
\hline 2 & Without my medicines I would be very ill. & 0 & $19(6.3)$ & $13(4.3)$ & $100(33.3)$ & $168(56.0)$ \\
\hline 3 & $\begin{array}{l}\text { My health, at present, depends on my } \\
\text { medicines }\end{array}$ & $1(0.3)$ & $20(6.7)$ & $8(2.7)$ & $136(45.3)$ & $135(45.0)$ \\
\hline 4 & $\begin{array}{l}\text { My medicines protect me from becoming } \\
\text { worse. }\end{array}$ & $1(0.3)$ & $16(5.3)$ & $14(4.7)$ & $134(44.7)$ & $135(45.0)$ \\
\hline \multirow[t]{2}{*}{5} & $\begin{array}{l}\text { My health in the future will depend on my } \\
\text { medicines. }\end{array}$ & $2(0.7)$ & $21(7.0)$ & $74(24.7)$ & $103(34.3)$ & $100(33.3)$ \\
\hline & Specific-Concern (BMQ-SC) & & & & & \\
\hline 6 & $\begin{array}{l}\text { I sometimes worry about long-term } \\
\text { effects of my medicines. }\end{array}$ & $11(3.7)$ & $101(33.7)$ & $12(4.0)$ & $134(44.7)$ & $42(14.0)$ \\
\hline 7 & Having to take medicines worries me. & $9(3.0)$ & $104(34.7)$ & $11(3.7)$ & $141(47.0)$ & $35(11.7)$ \\
\hline 8 & $\begin{array}{l}\text { I sometimes worry about becoming too } \\
\text { dependent on my medicines. }\end{array}$ & $10(3.3)$ & $100(33.3)$ & $9(3.0)$ & $148(49.3)$ & $33(11.0)$ \\
\hline 9 & My medicines disrupt my life & $14(4.7)$ & $60(20.0)$ & $2(0.7)$ & $152(50.7)$ & $72(24.0)$ \\
\hline \multirow[t]{2}{*}{10} & My medicines are a mystery to me. & $9(3.0)$ & $118(39.3)$ & $31(10.3)$ & $126(42.0)$ & $16(5.3)$ \\
\hline & General-Harm (BMQ-GH) & & & & & \\
\hline 11 & $\begin{array}{l}\text { People who take medicines should stop } \\
\text { their treatment for a while every now and } \\
\text { again. }\end{array}$ & $21(7.0)$ & $107(35.7)$ & $58(19.3)$ & $101(33.7)$ & $13(4.3)$ \\
\hline 12 & Most medicines are addictive. & $9(3.0)$ & $123(41.0)$ & $64(21.3)$ & $97(32.3)$ & $7(2.3)$ \\
\hline 13 & Medicines do more harm than good. & $22(7.3)$ & $135(45.0)$ & $51(17.0)$ & $81(27.0)$ & $11(3.7)$ \\
\hline \multirow[t]{2}{*}{14} & All medicines are poisons. & $18(6.0)$ & $113(37.7)$ & $76(25.3)$ & $83(27.7)$ & $10(3.3)$ \\
\hline & General-Overuse (BMQ-GO) & & & & & \\
\hline 15 & $\begin{array}{l}\text { Natural remedies are safer than } \\
\text { medicines. }\end{array}$ & $57(19.0)$ & $133(44.3)$ & $46(15.3)$ & $56(18.7)$ & $8(2.7)$ \\
\hline 16 & Doctors use too many medicines & $7(2.3)$ & $107(35.7)$ & $46(15.3)$ & $122(40.7)$ & $18(6.0)$ \\
\hline 17 & $\begin{array}{l}\text { Doctors place too much trust on } \\
\text { medicines }\end{array}$ & $4(1.3)$ & $60(20.0)$ & $44(14.7)$ & $169(56.3)$ & $23(7.7)$ \\
\hline 18 & $\begin{array}{l}\text { If doctors had more time with patients, } \\
\text { they would prescribe fewer medicines }\end{array}$ & $3(1.0)$ & $118(39.3)$ & $81(27.0)$ & $79(26.3)$ & $19(6.3)$ \\
\hline
\end{tabular}

*SN: specific necessity, SC: specific concern, GH: general harm, GO: general overuse.

Multiple linear regression analyses were used to measure the relationships between the four BMQ components (outcome variables) and 10 socio-demographic independent variables and five disease characteristics (independent variables), Gender was significantly $(P$-value $<0.05)$ and negatively associated with BMQ-SN. In other words, men had significantly lower perception of medicine specific necessity (BMQ-SN) compared to women. Patients with higher education had a significant $(P$-value< 0.05$)$ positive association with the beliefs of general overuse and general harm of medicines (Table 7). Psoriasis Area Surface Index (PASI) has a significant positive association with BMQ specific concern beliefs. Disease duration has significant positive association with BMQ-specific necessity, while it has a significant negative association with BMQ-general overuse (Table 8). 
Table 7: Association between BMQ components with socio-demographic variables

\begin{tabular}{|c|c|c|c|c|c|c|c|c|}
\hline \multirow[b]{2}{*}{ Demographics } & \multicolumn{2}{|c|}{$\begin{array}{r}\text { Specific } \\
\text { Necessity }\end{array}$} & \multicolumn{2}{|c|}{ Specific Concern } & \multicolumn{2}{|c|}{ General Overuse } & \multicolumn{2}{|c|}{ General Harm } \\
\hline & $\begin{array}{r}\text { Beta } \\
\text { Coeff. }\end{array}$ & $\begin{array}{r}p- \\
\text { value }\end{array}$ & $\begin{array}{l}\text { ßeta } \\
\text { Coeff. }\end{array}$ & $\begin{array}{r}p- \\
\text { value }\end{array}$ & $\begin{array}{l}\text { Beta } \\
\text { Coeff. }\end{array}$ & $p$-value & $\begin{array}{r}\text { Beta } \\
\text { Coeff. }\end{array}$ & $p$-value \\
\hline Age & & & -0.076 & 0.316 & 0.002 & 0.973 & -0.040 & 0.587 \\
\hline $\begin{array}{r}\text { Gender } \\
\text { (male/female) }\end{array}$ & -0.157 & $0.017^{*}$ & -0.032 & 0.686 & & - & 0.036 & 0.641 \\
\hline Educational level & -0.084 & 0.146 & -0.019 & 0.796 & 0.158 & $0.022 *$ & 0.265 & $0.000^{*}$ \\
\hline Social status & & - & 0.032 & 0.671 & -0.085 & 0.203 & 0.125 & 0.089 \\
\hline $\begin{array}{r}\text { Having children } \\
\text { (yes/no) }\end{array}$ & & - & -0.008 & 0.922 & & - & -0.109 & 0.156 \\
\hline $\begin{array}{r}\text { Living place } \\
\text { (urban/rural) }\end{array}$ & & - & 0.021 & 0.740 & 0.060 & 0.318 & 0.027 & 0.648 \\
\hline Work status & & - & -0.048 & 0.553 & 0.022 & 0.780 & 0.053 & 0.498 \\
\hline Monthly income & & - & 0.079 & 0.247 & 0.092 & 0.162 & -0.148 & 0.027 \\
\hline $\begin{array}{r}\text { Cigarette smokers } \\
\text { (yes/no) }\end{array}$ & 0.070 & 0.295 & -0.042 & 0.545 & & - & 0.039 & 0.562 \\
\hline $\begin{array}{r}\text { Alcohol drinker } \\
\text { (yes/no) }\end{array}$ & -0.062 & 0.302 & 0.083 & 0.173 & -0.031 & 0.581 & -0.049 & 0.413 \\
\hline
\end{tabular}

*Significant association ( $P$-value $<0.05)$. Gender $(0=$ female vs $1=$ male). Some highly non-significant variables $(P$-value $>0.6)$ (without mentioning $ß)$ had been excluded in some regression analyses to fit the model better. Types of psoriasis is binary variable $=(0=$ nonvulgaris / 1= vulgaris).

Table 8: Association between BMQ components and disease characteristics variables

\begin{tabular}{|r|r|r|r|r|r|r|r|r|}
\hline & \multicolumn{2}{|c|}{ Specific Necessity } & \multicolumn{2}{|c|}{ Specific Concern } & \multicolumn{2}{|c|}{ General Overuse } & \multicolumn{2}{c|}{ General Harm } \\
\hline Disease items & $\begin{array}{r}\text { ßeta } \\
\text { Coeff. }\end{array}$ & $\boldsymbol{p}$-value & $\begin{array}{r}\text { ßeta } \\
\text { Coeff. }\end{array}$ & $\boldsymbol{p}$-value & $\begin{array}{r}\text { ßeta } \\
\text { Coeff. }\end{array}$ & $\boldsymbol{p}$-value & $\begin{array}{r}\text { ßeta } \\
\text { Coeff. }\end{array}$ & $\begin{array}{r}\boldsymbol{p} \text { - } \\
\text { value }\end{array}$ \\
\hline PASI & 0.081 & 0.448 & 0.245 & $\mathbf{0 . 0 2 4}$ & 0.027 & 0.803 & 0.130 & 0.237 \\
\hline $\begin{array}{r}\text { BSA(\%) } \\
\text { Face included } \\
\text { (yes/no) }\end{array}$ & 0.063 & 0.542 & -0.154 & 0.141 & 0.016 & 0.876 & -0.078 & 0.459 \\
\hline $\begin{array}{r}\text { Disease } \\
\text { duration(yrs.) }\end{array}$ & 0.179 & $\mathbf{0 . 0 0 2 *}$ & -0.036 & 0.537 & -0.124 & $\mathbf{0 . 0 3 4}$ & -0.021 & 0.722 \\
\hline $\begin{array}{r}\text { Types of } \\
\text { psoriasis } \\
\text { (vulgaris/ other } \\
\text { types) }\end{array}$ & -0.025 & 0.633 & -0.061 & 0.291 & -0.002 & 0.973 & -0.090 & 0.122 \\
\hline
\end{tabular}

* PASI: Psoriasis Area and Severity Index, BSA: Body surface area. *Significant $(P$-value< 0.05$)$.

Types of psoriasis is binary variable ( $0=$ non-vulgaris/1=vulgaris). 


\section{Discussion}

This study examined the possible relations between medications belief and some patient's-related factors, where psoriasis is a suitable example of a complex state that considerable medication challenges as characterized by relapsing-remitting symptoms ${ }^{(17)}$. The BMQ was adequately designed for use in psoriasis (Thorneloe et al., 2017) ${ }^{(25)}$, and also recognized as being important in understanding the complexities of supporting patients with a long-term skin disease as effectively as possible ${ }^{(26)}$.

The predominant psoriasis type was psoriasis vulgaris $77.7 \%$, which is consistent with the findings of other studies done in Mexico ${ }^{(27)}$, Morocco ${ }^{(28)}$ and Malaysia ${ }^{(29)}$, where the psoriasis vulgaris was the most common type of psoriasis.

The most common type of medications prescribed for patients involved in the current study were topical steroids (63\%) followed by systemic etanercept (61.7\%). Topical therapies were recommended as first-line treatment in the current guidelines. It can be used alone or as adjunctive agents with systemic treatment in order to get better therapeutic outcomes (30). Most patients in this study had moderate or severe psoriasis, so most of them receive topical steroids with one or two of systemic therapies such as biologics and methotrexate as shown in table 2 where (63\%) of patients receive topical steroids, (61.7\%) take etanercept, and (22.7\%) receive methotrexate. Biological therapy had shown to be effective, improved symptoms when compared with conventional systemic treatments. Additionally, biologic drugs have fewer contraindications, lack of drug interactions and reduced toxicity (31).

The average disease duration in the current study was $13.12( \pm 8.6)$ years, which is lower than that reported by a study in Germany, which was 21.4 ( \pm 15.3 ) years ${ }^{(32)}$. This difference may be because patients with other chronic diseases (mostly were older patients with long disease duration) were excluded from the current study to meet inclusion criteria in order to obtain beliefs about psoriasis medications clearly. In general, BSA and PASI are commonly used to assess the activity of psoriasis ${ }^{(33)}$. For patients of the current study, the mean of disease severity estimated by PASI was $8.74( \pm 7.15)$, which approximate that reported by a German study $9.4( \pm 8.8)^{(32)}$. In contrast, a Moroccan study recorded a higher mean of PASI $11.8( \pm 7.9)^{(28)}$. In terms of BSA, the mean affected BSA was $17.25 \%( \pm 17.35)$, which is higher than result of the Brazilian study where the mean BSA was $12.7 \%( \pm 15.8)^{(34)}$. In the current study, approximately one-half of patients had moderate psoriasis, which differs from that reported by a study in Turkey where the psoriasis severity was "mild" in $63 \%$ of patients ${ }^{(35)}$.

In the current study, there was a positive belief about the necessity of medications represented by the specific-necessity score that showed the highest mean score followed by the specific-concern score. In addition, about three quarters of the patients $76.7 \%$ had BMQ specific-necessity score more than that of BMQ specific- concern. A study in the Netherlands found that most psoriatic patients using biologics were having (Necessity > Concern) beliefs ${ }^{(12)}$.

The high BMQ specific-necessity score could be explained by the long history of psoriasis therapies which can result in feelings of dependency on their therapy ${ }^{(12)}$. Psoriasis medications are important to control the disease, so it is unsurprising the fact that several patients rated their beliefs on the necessity of taking medications greater than concerns about the medication (36). Additionally, the positive belief about the necessity is reflected by the answers of the item "My health, at present, depends on my medicines" where approximately $90 \%$ of responses were 'agree', or 'strongly agree'.

Regarding the question (My health in the future will depend on my medicines), about two third of the participants $67.6 \%$ answered by 'agree', or 'strongly agree'. This result is similar to that reported by A study in the Netherlands where $58 \%$ of psoriatic patients in the biologics group believed that their health in the future will be dependent upon their psoriasis medication ${ }^{(12)}$. This can be explained by that most patients concerned that their condition characterized by remission and exacerbation ${ }^{(3)}$ so they believed for needing treatment in the future of their life.

In the necessity scale, results showed that female patients had higher beliefs in the necessity of psoriasis medications than male patients. Additionally, there was a significant positive association between specific necessity and disease duration, and a negative association with general over use. Similarly, a study done by in Netherlands, found that gender and treatment duration were possibly associated with the necessity scale ${ }^{(12)}$. A possible explanation may be that females are more affected by disease condition and overwhelmed with their appearance as shown in the table 8 where male has a significant negative association with specific necessity (need to medications) as compared with female. Also patients with longer treatment duration, have higher belief in the necessity of therapy in their life and lower belief about over use of medications due to their need to treatment for a long period in their lives, and not concern about how much used medication rather than wanted to recover.

In the concern scale, most patients reported concerns on all items, where more than one half of patients answered to all questions with agree and strongly agree, which is not consistent with the results reported by a study in Netherlands were most patients reported no concerns on all items ${ }^{(12)}$.

In this study, the PASI score was associated with the concern scale. This means that the higher the PASI score at the time of the survey, the higher the concern score for potential adverse effects of medication. A possible explanation is that patients with higher PASI (more severe disease) required to be treated 
by systemic drugs, which associated with more serious adverse effects compared to topical therapies in case of mild disease. In addition, there was a direct correlation between educational level and general over use and harm subscales. A possible explanation for these findings could be that having a higher educational level may be associated with more awareness about medication composition and side effects.

\section{Conclusions}

Most of the psoriatic patients involved in the current study had strong beliefs in the necessity of their treatment to control psoriasis, which causes acceptance of the medications. Female gender and longer disease duration have a direct association with specific necessity, while psoriasis severity has a direct association with specific concern. Higher beliefs related to medicines overused and harm are associated with higher educational levels. Beliefs of medication and habit strength are important modifiable drivers to enhance adherence and clinical outcomes in the control of psoriasis.

\section{Limitations of the study}

Firstly, patients were recruited from only one center in one Iraqi governorate. Future study about psoriasis can be performed as multicenter studies to recruit patients from different dermatological centers across the country. Secondly, the study focused on patients referred by their primary care medical service providers or actively seeking care and may not be extended to those untreated in the general population. Finally, there was a limited number of studies measuring belief about medicine in psoriatic patients. This made it difficult to compare the results of the current study with other studies.

\section{References}

1. Wu T, Duan X, Chen S, Chen X, Yu R, Yu X. Association Between Psoriasis and Erectile Dysfunction: A MetaAnalysis. J Sex Med 2018;15(6):839-47.

2. Alidrisi HA, Al Hamdi K, Mansour AA. Is There Any Association Between Psoriasis and Hashimoto's Thyroiditis? Cureus. 2019;11(3):1-15.

3. Aldeen A, Murad K, Mohammed W, Fibms H. Incidance of Psoriasis in Patients with Different Skin in Baquba City Abstract. 2017;12(1):25-28

4. Al-imam AML. A Case of Remitting Psoriasis in Association with Hyperthyroidism in a Morbidly Obese Iraqi Female. 2017;2(1):1-4

5. Khadhim MM, Ali Al. Associations of Specific HLA-C Loci and Sociodemographic Factors with the Prevalence of Type I Psoriasis in Iraqi Patients. Nano Biomed Eng. 2018; 10(4): 328-33.

6. Takeshita J, Grewal S, Langan SM, Mehta NN, Ogdie A, Van Voorhees AS, et al. Psoriasis and comorbid diseases: Epidemiology. J Am Acad Dermatol. 2017;76(3):377-90.

7. Ahronowitz I and Fox LP. Severe drug-induced dermatoses. Semin Cutan Med Surg. 2014;33(1):4958.
8. Moradi M. Health-related quality of life and disease burden of psoriasis in Iran. 2017. PhD Thesis. Budapesti Corvinus Egyetem.

9. Kuba RH, Al-qadhi BN, Fadheel BM. Effect of the Biological Drug Etanercept on Tumor necrosis factor$\alpha$ Levels in Psoriatic Patients. Iraqi J Sci. 2018;59(2C):998-1005.

10. Aldredge LM, Higham RC. Manifestations and Management of Difficult-to-Treat Psoriasis. J Dermatol Nurses Assoc. 2018;10(4):189-97.

11. Menter A, Korman NJ, Elmets CA, Feldman SR, Gelfand JM, Gordon KB, et al. Guidelines of care for the management of psoriasis and psoriatic arthritis. Section 3. Guidelines of care for the management and treatment of psoriasis with topical therapies. J Am Acad Dermatol.2009;60(4):643-59.

12. Otero ME, Van Den Reek JMPA, Van De Kerkhof PCM, Mertens JS, Seyger MMB, Kievit W, et al. Beliefs about medicines in patients with psoriasis treated with methotrexate or biologics: A cross-sectional survey study. Acta Derm Venereol. 2019;99(4):38692.

13. Wei L, Champman S, Li X, Li X, Li S, Chen R, et al. Beliefs about medicines and non-adherence in patients with stroke, diabetes mellitus and rheumatoid arthritis: A cross-sectional study in China. BMJ open. 2017;7(10):1-9.

14. Abdulrahman $\mathrm{N}$, Alsubeeh, Alsharafi AA, Ahamed SS, Alajlan A. Treatment adherence among patients with five dermatological diseases and four treatment types-a cross-sectional study. Patient Prefer Adherence. 2019;13:2029-38.

15. Linn AJ, van Weert JCM, Gebeyehu BG, Sanders R, Diviani N, Smit EG, et al. Patients' Online InformationSeeking Behavior Throughout Treatment: The Impact on Medication Beliefs and Medication Adherence. Health Commun. 2019;34(12):1461-8.

16. Faiq MK, Kadhim DJ, Gorial FI. Belief about medicines among a sample of Iraqi patients with rheumatoid arthritis. Iraqi J Pharm Sci. 2019;28(2):134-41.

17. Thorneloe RJ, Griffiths CEM, Ashcroft DM, Cordingley L. The challenges of assessing patients' medication beliefs: a qualitative study. BMC Health Serv Res. 2017;17(1):1-11.

18. Tsianou K, Giannakeas N, Tsipouras MG, Tzallas AT, Skamnelos A, Christodoulou DK, et al. Accessing Patient Views about Medication in Chronic Conditions using the Beliefs about Medicine Questionnaire (BMQ): A Review Study. J Drug Res Dev. 2017;3(2):19.

19. Ko WC, Tsai TF and Tang $\mathrm{CH}$. Health state utility, willingness to pay, and quality of life among Taiwanese patients with psoriasis. Dermatologica Sin. 2016;34(4):185-91. 
20. Supramaniam $P$, binti Ali A, Li Yun C, Pei Yi C, binti Shaari A, binti Kamaruzaman $\mathrm{NH}$, et al. Reliability and validity of Beliefs on Medicine Questionnaire (BMQ) in diabetes mellitus patients: Malay Translated Version. Int J Sci Res Publ. 2019;9(2):66-73.

21. Salame N, Perez-Chada LM, Singh S, Duffin KC, Garg A, Alice B. Gottlieb $A B$, et al. Are your patients satisfied a systematic review of treatment satisfaction measures in psoriasis. Dermatology. 2014;234(56):157-65.

22. Smolen, Josef S, Gladman, Dafna McNeil, H. Patrick Mease, Philip J. Sieper et al. Predicting adherence to therapy in rheumatoid arthritis, psoriatic arthritis or ankylosing spondylitis: A large cross-sectional study. 2019;5(1):1-13.

23. AlHewiti A. Adherence to Long-Term Therapies and Beliefs about Medications. Int J Family Med. 2014:18.

24. Horne R, Graupner L, Frost S, Weinman J, Wright SM, Hankins M. Medicine in a multi-cultural society: The effect of cultural background on beliefs about medications. Soc Sci Med. 2004;59(6):1307-13.

25. Thorneloe RJ, Griffiths CEM, Emsley R, Ashcroft DM, Cordingley L, Barker J, et al. Intentional and Unintentional Medication Non-Adherence in Psoriasis: The Role of Patients' Medication Beliefs and Habit Strength. J Invest Dermatol. 2018;138(4):78594.

26. Cowdell F. Commentary on an exploratory study to investigate health seeking behaviour in patients with psoriasis using framework analysis. BJD.2017;177(3):615-616.

27. García-Sánchez L, Montiel-Jarquín Á.J, Vázquez-Cruz E, May- Salazar A, Gutiérrez-Gabriel I, and LoríaCastellanos J. Quality of life in patients with psoriasis. Gaceta medica de Mexico.2017;153(2):185189.

28. Khoudri I, Lamchahab FZ, Ismaili N, Senouci K, Hassam B, Abouqal R. Measuring quality of life in patients with psoriasis using the Arabic version for Morocco of the Dermatology Life Quality Index. Int J Dermatol. 2013;52(7):795-802.

29. Affandi AM, Khan I, Saaya NN. Epidemiology and Clinical Features of Adult Patients with Psoriasis in Malaysia: 10-Year Review from the Malaysian Psoriasis Registry (2007-2016). Dermatol Res Pract. 2018; 2018:1-8.

30. Segaert $S$, Calzavara-Pinton $P$, de la Cueva $P$, Jalili $A$, Lons Danic D, Pink AE, et al. Long-term topical management of psoriasis: the road ahead. J Dermatolog Treat.2020:1-10.

31. Mantovani L, Medaglia M, Piacentini P, Tricca M, Vena GA, Vozza A, et al. Burden of Moderate-toSevere Plaque Psoriasis and New Therapeutic Approaches (Secukinumab): An Italian Perspective. Dermatol Ther (Heidelb). 2016;6(2):151-67.
32. Augustin M, Langenbruch A, Gutknecht M, Reich K, Körber A, Maaßen D, et al. Definition of psoriasis severity in routine clinical care: current guidelines fail to capture the complexity of long-term psoriasis management. Br J Dermatol. 2018;179(6):1385-91.

33. Youn SW, Lee JH, Yu DY, Kim Y, Kim BS, Seo SJ, et al. The relationship between clinical characteristics including presence of exposed lesions and healthrelated quality of life (HRQoL) in patients with psoriasis: analysis from the nationwide epidemiologic study for psoriasis in Korea (EPI-PSODE study). Journal of the European Academy of Dermatology and Venereology. 2018:32(9):1499-1506.

34. Souza CS, de Castro CCS, Carneiro FRO, Pinto JMN, Fabricio LHZ, Azulay-Abulafia L, et al. Metabolic syndrome and psoriatic arthritis among patients with psoriasis vulgaris: Quality of life and prevalence. J Dermatol. 2019;46(1):3-10.

35. Çakmur H, Derviş E. The relationship between quality of life and the severity of psoriasis in Turkey. Eur J Dermatology. 2015;25(2):169-76.

36. Liu H-X, Teng S, Lin X-H, Shang Y-B, Wang L, Zhang J, et al. The application of the necessity-concerns framework in investigating adherence and beliefs about immunosuppressive medication among Chinese liver transplant recipients. Chinese Nurs Res. 2017;4(1):14-7. 